\title{
DAMPAK SOSIAL KESEHATAN GIGI DAN MULUT PADA LANSIA DI UPT PELAYANAN SOSIAL LANJUT USIA BINJAI
}

\author{
(SOCIAL IMPACT OF ORAL HEALTH AMONG ELDERLY \\ AT UPT PELAYANAN SOSIAL LANJUT USIA IN BINJAI)
}

\author{
Sondang Pintauli, Lina Maria \\ Departemen Ilmu Kedokteran Gigi Pencegahan/ Kesehatan Gigi Masyrakat \\ Fakultas Kedokteran Gigi, Universitas Sumatera Utara \\ Jl. Alumni No 2 Kampus USU Medan 20155
}

\begin{abstract}
The aging process can affect the oral health of elderly, such as changes in the mucosa of the mouth, dry mouth, dental caries and attrition, gingival recession, and periodontal changes caused alveolar bone mobiliti and tooth loss. This condition can affect the quality of life of the elderly. The purpose of this study was to determine the social impact of the oral health in the elderly at Elderly Social UPT Binjai using the Geriatric Oral Health Assessment Index (GOHAI). The populations in this cross-sectional study were 160 people, while the sample was selected based on the inclusion criteria and obtained as many as 87 people. Based on physical function, most of the respondents reported that the kinds and amount of food they consumed were limited (77.0\%), had trouble biting or chewing food (75.9\%), and trouble when speaking (57.5\%). In pain or discomfort dimension, 43.7 percent respondents had discomfort when eating and 19.5 percent sensitive to hot and cold on their gingiva and teeth. Only $1.1 \%$ respondents always use medication to relieve pain or discomfort. In psychosocial dimension, 36.8\% respondents reported always unhappy/unpleasant with the look of their teeth/denture, $34.5 \%$ never worried and concerned about their teeth/denture, 39.1\% always self-confidence and $36.8 \%$ always feel comfort when contact with other people. The number of teeth could affect a person's quality of life $(p<0,001)$. It is concluded that the quality of life among elderly with less missing teeth was found to be more favorable and vice versa.
\end{abstract}

Key words: quality of life, GOHAI, number of teeth, elderly

\begin{abstract}
Abstrak
Proses penuaan dapat mempengaruhi kondisi kesehatan gigi dan mulut pada lansia, misalnya perubahan pada mukosa mulut, mulut kering, karies gigi dan atrisi, resesi gingiva dan perubahan periodontal yang menyebabkan tulang alveolar mengalami mobiliti dan akhirnya kehilangan gigi. Keadaan ini akan mempengaruhi kualitas hidup lansia. Tujuan penelitian ini adalah untuk menentukan dampak sosial kesehatan gigi dan mulut lansia yang tinggal di UPT Pelayanan Sosial Lanjut Usia Binjai dengan menggunakan indeks Geriatic Oral Health Assessment (GOHAI). Populasi penelitian pada penelitian potong lintang ini adalah 160 orang, sedangkan sampel dipilih berdasarkan kriteria inklusi dan diperoleh sebanyak 87 orang. Hasil penelitian menunjukkan pada dimensi fungsi fisik yang selalu dialami responden adalah membatasi makanan (77\%), kesulitan menggigit atau mengunyah makanan $(75,9 \%)$ dan masalah dalam berbicara (57,5\%). Pada dimensi rasa sakit dan ketidaknyamanan, sebanyak 43,7\% responden merasa tidak nyaman waktu makan, dan $19.5 \%$ selalu merasa sensitif terhadap panas, dingin dan manis. Hanya 1,1\% yang sering/selalu menggunakan obatobatan untuk menghilangkan rasa sakit. Pada dimensi psikososial, 36,8\% responden tidak pernah merasa senang dengan penampilan mereka karena masalah pada gigi, sedangkan 34,5\% tidak pernah merasa khawatir dengan masalah pada giginya, 39,1\% selalu percaya diri dan 36,8\% selalu merasa nyaman bersosialisasi dengan orang lain. Jumlah gigi mempengaruhi kualitas hidup ( $<<0,001$ ). Dapat disimpulkan bahwa kualitas hidup lansia yang mengalami kehilangan gigi sedikit akan lebih baik dan sebaliknya.
\end{abstract}

Kata kunci: kualitas hidup, GOHAI, jumlah gigi, lansia

\section{PENDAHULUAN}

Kesehatan merupakan aspek penting dari kualitas hidup manusia dan segala upaya kesehatan yang bertujuan untuk mencapai taraf hidup dan derajat kesehatan yang optimal. Bertambahnya jumlah pen- 
duduk di Indonesia serta meningkatnya usia harapan hidup, akan diikuti pula dengan meningkatnya jumlah penduduk lanjut usia (lansia). Badan Pusat Statistik (BPS) mencatat jumlah penduduk lansia di Indonesia tahun 2000 mencapai lebih dari 14 juta orang atau sekitar 7\% dari total jumlah penduduk. Jumlah tersebut akan diperkirakan mencapai 30 hingga 40 juta pada tahun $2020{ }^{1}$

Masalah kesehatan adalah masalah yang paling sering dihadapi oleh lansia. Penyebab penyakit pada golongan lansia disebabkan karena menurunnya fungsi berbagai alat tubuh karena proses penuaan. Sel-sel banyak diganti, produksi hormon menurun dan produksi zat-zat untuk daya tahan tubuh juga menurun. ${ }^{2,3}$

Dampak proses penuaan ini dapat mempengaruhi kondisi kesehatan gigi dan mulut pada lansia, seperti perubahan pada mukosa mulut yang memudahkan terjadinya lesi dan kelainan pada lidah, terjadinya mulut kering (xerostomia) yang disebabkan karena perubahan atrofi pada kelenjar saliva sesuai dengan pertambahan usia yang akan menurunkan produksi saliva, gigi yang mengalami atrisi dan meningkatnya karies akar gigi yang berhubungan dengan meningkatnya resesi gingiva, perubahan jaringan periodontal, meningkatnya mobiliti (gigi goyang), serta resorbsi jaringan tulang alveolar akibat perubahan fisiologis pada proses penuaan jaringan sehingga menyebabkan kehilangan gigi. ${ }^{4,5}$

Perubahan-perubahan pada rongga mulut lansia ini merupakan proses degenerasi yang dapat mempengaruhi kualitas hidupnya, misalnya dalam aktivitas keseharian seperti penurunan waktu tidur, gangguan asupan makanan, dan gangguan psikologis yang berhubungan dengan menurunnya kepercayaan diri. Athinson dkk menggunakan Geriatric Oral health Assessment Index (GOHAI) untuk mengukur kualitas hidup yang berhubungan dengan kondisi rongga mulut pada lansia di Amerika Utara. GOHAI terdiri atas tiga dimensi yaitu dimensi fungsi fisik yang ditandai dengan membatasi makanan, kesulitan menggigit dan mengunyah, masalah dalam menelan dan masalah dalam berbicara. Dimensi rasa sakit/ketidaknyamanan ditandai dengan merasakan ketidaknyamanan ketika makan, menggunakan obat obatan untuk menghilangkan rasa sakit dan merasakan kesensitifan ketika makan makanan panas, dingin dan manis, sedangkan pada dimensi psikososial ini erat kaitannya dengan hubungan sosial terhadap orang lain/masyarakat, yaitu membatasi hubungan dengan orang lain, tidak senang dengan penampilan gigi/gusi/gigi palsu, merasa khawatir dengan keadaan gigi/gusi/gigi palsu, tidak percaya diri dengan keadaan gigi/gusi/gigi palsu dan merasa tidak nyaman dengan orang lain karena masalah gi- gi/gusi/ gigi palsu. ${ }^{6-8}$

Pengukuran dampak sosial semakin penting sebagai respons terhadap makin meningkatnya penyakit-penyakit kronis maupun penyakit degenerasi. Pengukuran dampak sosial juga dapat memonitor kecenderungan kesehatan penduduk dalam ruang dan waktu, mengevaluasi pengaruh kebijakan dalam bidang kesehatan, mendiagnosis penyakit dan keparahannya, melihat perubahan kualitas hidup setelah masa tertentu serta mengevaluasi pengaruh perawatan yang dilakukan. ${ }^{9}$

\section{BAHAN DAN METODE}

Jenis penelitian ini adalah cross sectional study. Populasi dalam penelitian ini adalah semua lansia berjumlah \pm 160 orang yang berada di UPT Pelayanan Sosial Lanjut Usia Binjai.

Sampel dalam penelitian ini dipilih berdasarkan kriteria inklusi yaitu: lansia elderly berusia 60-74 tahun (WHO), sehat jasmani dan rohani, bersedia diperiksa rongga mulutnya dan diwawancarai. Sampel yang diperoleh berdasarkan kriteria inklusi yaitu sebesar 87 orang. Indeks dampak sosial yang dipakai adalah indeks GOHAI (geriatric oral health index) yang pengukurannya 3 dimensi yaitu, fungsi fisik, rasa sakit/ketidaknyaman dan psikososial yang dibuat oleh Atchinson dan Dolan. ${ }^{8}$

Pengumpulan data dilakukan dengan wawancara menggunakan alat bantu kuesioner GOHAI yang terdiri atas 12 pertanyaan. Jawaban dibuat dalam dalam bentuk skala Likert (1-5): Skor 0 menyatakan tidak pernah, skor 1 menyatakan hampir tidak pernah dalam seminggu, skor 2 menyatakan jarang yaitu hampir tidak pernah dalam seminggu ( \pm 1 kali dalam seminggu), skor 3 menyatakan kadangkadang yaitu mengalami \pm 3 kali dalam seminggu, skor 4 menyatakan sering yaitu hampir tiap kali dalam seminggu ( \pm 5 kali dalam seminggu), skor 5 menyatakan selalu yaitu mengalami setiap kali dalam seminggu.

Data yang diperoleh diedit dan dianalisis untuk melihat hubungan antara jumlah gigi yang sehat dengan dampak sosial (GOHAI) menggunakan uji Chi square.

\section{HASIL}

Pada Tabel 1 terlihat persentase responden yang terbanyak berusia $>65$ tahun yaitu 78,2\%. Sedangkan yang berusia 60-64 tahun 21,8\%. Berdasarkan jenis kelamin, responden yang terbanyak adalah perempuan yaitu $62,1 \%$, dengan jumlah gigi sehat yang ada yaitu pada kategori 1-10 gigi sebanyak $49,4 \%$. 
Tabel 1. Karakteristik responden lansia di UPT Pelayanan Sosial Lanjut Usia Binjai $(n=87)$

\begin{tabular}{lcc}
\hline Karakteristik & Jumlah & Persentase \\
\hline Usia (tahun) & & \\
$60-64$ & 19 & 21,8 \\
$>65$ & 68 & 78,2 \\
& & \\
Jenis kelamin & 33 & 37,9 \\
Laki-laki & 54 & 62,1 \\
Perempuan & & \\
& & \\
Jumlah gigi sehat yang ada & 20 & 22,9 \\
Tidak ada gigi & 43 & 49,4 \\
1-10 gigi & 17 & 19,5 \\
11-20 gigi & 7 & 8,1 \\
$>$ 21 gigi & & \\
\hline
\end{tabular}

Pada Tabel 2 persentase lansia yang mengalami mobiliti gigi di rongga mulut adalah $32,2 \%$, mulut kering $31 \%$, dan atrisi $19,5 \%$

Tabel 2. Persentase kondisi rongga mulut pada lansia di UPT Pelayanan Sosial Lanjut Usia Binjai $(n=87)$

\begin{tabular}{lcccc}
\hline \multirow{2}{*}{$\begin{array}{l}\text { Kondisi rongga } \\
\text { mulut }\end{array}$} & $\mathrm{n}$ & $\%$ & $\mathrm{n}$ & $\%$ \\
\hline Gigi mobility & 28 & 32,2 & 59 & 31,0 \\
Mulut kering & 27 & 19,5 & 60 & 67,8 \\
Lain-lain (atrisi) & 17 & 69,0 & 70 & 80,5 \\
\hline
\end{tabular}

Rerata pengalaman karies keseluruhan responden adalah 19,1 $\pm 7,6$. Skor DMFT pada keseluruhan responden laki-laki lebih tinggi yaitu $21,3 \pm 7,4$, sedangkan responden perempuan $17,7 \pm 7,3$. Skor pengalaman karies tertinggi adalah skor missing, yaitu pada laki-laki 20,5 $\pm 7,5$ sedangkan pada perempuan $16,61 \pm 7,7$.

Tabel 3. Rerata DMFT berdasarkan jenis kelamin pada lansia di UPT Pelayanan Sosial Lanjut Usia Binjai

\begin{tabular}{|c|c|c|c|c|c|c|c|c|c|}
\hline \multirow{3}{*}{$\begin{array}{l}\text { Jenis } \\
\text { kelamin }\end{array}$} & \multicolumn{8}{|c|}{ Pengalaman karies } & \multirow{3}{*}{$\mathrm{n}$} \\
\hline & \multicolumn{2}{|c|}{$\mathrm{D}$} & \multicolumn{2}{|c|}{$\mathrm{M}$} & \multicolumn{2}{|c|}{$\mathrm{F}$} & \multicolumn{2}{|c|}{ DMFT } & \\
\hline & $X$ & SD & $X$ & SD & $X$ & SD & $X$ & SD & \\
\hline Laki-laki & 0,9 & 0,9 & 20,5 & 7,5 & - & - & 21,3 & 7,4 & 33 \\
\hline Perempuan & 1,0 & 1,3 & 16,6 & 7,7 & 0,1 & 0,3 & 17,7 & 7,3 & 54 \\
\hline Total & 0,9 & 1,2 & 18,1 & 7,9 & 0,1 & 0,3 & 19,1 & 7,6 & 87 \\
\hline
\end{tabular}

Tabel 4 menunjukkan bahwa persentase paling banyak yaitu lansia yang mempunyai $1-10$ gigi $49,4 \%$, sedangkan lansia yang mempunyai $>21$ gigi hanya $8,0 \%$, dan lansia yang tidak mempunyai gigi ada $23 \%$.
Tabel 4. Persentase jumlah gigi sehat berdasarkan usia lansia di UPT Pelayanan Sosial Lanjut Usia Binjai

\begin{tabular}{cccccccccc}
\hline \multirow{2}{*}{$\begin{array}{l}\text { Usia } \\
\text { (tahun) }\end{array}$} & $\begin{array}{c}\text { Tidak } \\
\text { ada gigi }\end{array}$ & \multicolumn{2}{c}{$\begin{array}{c}\text { 1-10 } \\
\text { gigi }\end{array}$} & \multicolumn{2}{c}{$\begin{array}{c}\text { gigi } \\
\text { gigi }\end{array}$} & \multicolumn{2}{c}{$>$ gigi } & \multirow{2}{*}{ Total } \\
\cline { 2 - 7 } & $\mathrm{n}$ & $\%$ & $\mathrm{n}$ & $\%$ & $\mathrm{n}$ & $\%$ & $\mathrm{n}$ & $\%$ & \\
\hline $60-64$ & 2 & 2,3 & 8 & 9,2 & 6 & 6,9 & 4 & 4,6 & 19 \\
$>65$ & 18 & 20,7 & 35 & 40,2 & 11 & 12,6 & 3 & 3,4 & 68 \\
\hline Total & 20 & 23 & 43 & 49,4 & 17 & 19,5 & 7 & 8,0 & 87 \\
\hline
\end{tabular}

Untuk gangguan kualitas hidup pada dimensi fungsi fisik, persentase yang selalu dialami oleh responden berturut-turut adalah membatasi makanan $(77,0 \%)$, kesulitan menggigit dan mengunyah $(75,9 \%)$, masalah dalam berbicara $(57,5 \%)$, dan masalah dalam menelan $(27,6 \%$ ) (Tabel 5).

Tabel 5. Kualitas hidup responden berdasarkan dimensi fungsi fisik pada lansia di UPT Pelayanan Sosial Lanjut Usia Binjai $(n=87)$

\begin{tabular}{|c|c|c|c|c|c|c|c|c|c|c|}
\hline \multirow[t]{2}{*}{$\begin{array}{l}\text { Dimensi } \\
\text { fungsi fisik }\end{array}$} & \multicolumn{2}{|c|}{$\begin{array}{l}\text { Tidak } \\
\text { pernah } \\
\text { (1) }\end{array}$} & \multicolumn{2}{|c|}{$\begin{array}{c}\text { Jarang } \\
\text { (2) }\end{array}$} & \multicolumn{2}{|c|}{$\begin{array}{l}\text { Kadang- } \\
\text { kadang } \\
\text { (3) }\end{array}$} & \multicolumn{2}{|c|}{$\begin{array}{l}\text { Sering } \\
\text { (4) }\end{array}$} & \multicolumn{2}{|c|}{$\begin{array}{l}\text { Selalu } \\
\text { (5) }\end{array}$} \\
\hline & $\mathrm{n}$ & $\%$ & $\mathrm{n}$ & $\%$ & $\mathrm{n}$ & $\%$ & $\mathrm{n}$ & $\%$ & $\mathrm{n}$ & $\%$ \\
\hline $\begin{array}{l}\text { Membatasi } \\
\text { makanan }\end{array}$ & 9 & 10,3 & 1 & 1,1 & 5 & 5,7 & 5 & 5,7 & 67 & 77,0 \\
\hline $\begin{array}{l}\text { Kesulitan } \\
\text { menggigit \& } \\
\text { mengunyah }\end{array}$ & 9 & 10,3 & 2 & 2,3 & 3 & 3,4 & 7 & 8,0 & 66 & 75,9 \\
\hline $\begin{array}{l}\text { Masalah da- } \\
\text { lam menelan }\end{array}$ & 4 & 4,6 & 8 & 9,2 & 21 & 24,1 & 30 & 34,5 & 24 & 27,6 \\
\hline $\begin{array}{l}\text { Masalah da- } \\
\text { lam berbicara }\end{array}$ & 19 & 21,8 & 3 & 3,4 & 9 & 10,3 & 6 & 6,9 & 50 & 57,5 \\
\hline
\end{tabular}

Pada dimensi rasa sakit/ketidaknyamanan, hampir setengah responden yang tidak pernah merasa nyaman ketika makan yaitu $43,7 \%$. Responden yang selalu menggunakan obat-obatan hanya $1,1 \%$, dan responden yang selalu mengalami sensitif terhadap makanan panas, dingin dan manis $19,5 \%$ sedangkan yang tidak pernah sebanyak $71,3 \%$ (Tabel 6).

Tabel 6. Kualitas hidup responden berdasarkan dimensi rasa sakit/ketidaknyamanan pada lansia di UPT Pelayanan Sosial Lanjut Usia Binjai $(n=87)$

\begin{tabular}{|c|c|c|c|c|c|c|c|c|c|c|}
\hline \multirow[t]{2}{*}{$\begin{array}{l}\text { Dimensi rasa } \\
\text { sakit/ketidak } \\
\text { nyamanan }\end{array}$} & \multicolumn{2}{|c|}{$\begin{array}{c}\text { Tidak } \\
\text { pernah } \\
(1)\end{array}$} & \multicolumn{2}{|c|}{$\begin{array}{c}\text { Jarang } \\
\text { (2) }\end{array}$} & \multicolumn{2}{|c|}{$\begin{array}{l}\text { Kadang- } \\
\text { kadang } \\
\text { (3) }\end{array}$} & \multicolumn{2}{|c|}{$\begin{array}{l}\text { Sering } \\
\text { (4) }\end{array}$} & \multicolumn{2}{|c|}{$\begin{array}{c}\text { Selalu } \\
\text { (5) }\end{array}$} \\
\hline & $\mathrm{n}$ & $\%$ & $\mathrm{n}$ & $\%$ & $\mathrm{n}$ & $\%$ & $\mathrm{n}$ & $\%$ & $\mathrm{n}$ & $\%$ \\
\hline $\begin{array}{l}\text { Nyaman ke- } \\
\text { tika makan }\end{array}$ & 38 & 43,7 & 25 & 28,7 & 11 & 12,6 & 7 & 8,0 & 6 & 6,9 \\
\hline $\begin{array}{l}\text { Menggunakan } \\
\text { obat-obatan } \\
\text { untuk meng- } \\
\text { hilangkan rasa } \\
\text { sakit }\end{array}$ & 77 & 88,5 & 3 & 3,4 & 5 & 5,7 & 1 & 1,1 & 1 & 1,1 \\
\hline $\begin{array}{l}\text { Sensitif ter- } \\
\text { hadapmakana } \\
\text { panas, dingin, } \\
\& \text { manis }\end{array}$ & 67 & 71,3 & 4 & 4,6 & 1 & 1,1 & 3 & 3,4 & 17 & 19,5 \\
\hline
\end{tabular}


Untuk dimensi psikososial, persentase responden yang tidak pernah membatasi hubungan dengan orang lain yaitu $57,5 \%$, tidak pernah merasa khawatir dengan penampilan gigi/gusi/gigi palsu yaitu $34,5 \%$, selalu percaya diri dengan gigi/gusi/ gigi palsu yaitu $39,1 \%$, merasa nyaman dengan orang lain karena gigi/gusi/gigi palsu yaitu 36,8\%. Walaupun demikian ada juga yang merasa tidak pernah senang dengan penampilan gigi/gusi/gigi palsunya yaitu $36,8 \%$, sedangkan yang selalu merasa senang hanya $10,3 \%$ (Tabel 7).

Tabel 7. Kualitas hidup responden berdasarkan dimensi psikososial pada lansia di UPT Pelayanan Sosial Lanjut Usia Binjai $(n=87)$

\begin{tabular}{|c|c|c|c|c|c|c|c|c|c|c|}
\hline \multirow[t]{2}{*}{ Dimensi psikososial } & \multicolumn{2}{|c|}{$\begin{array}{l}\text { Tidak } \\
\text { pernah } \\
\text { (1) }\end{array}$} & \multicolumn{2}{|c|}{$\begin{array}{c}\text { Jarang } \\
\text { (2) }\end{array}$} & \multicolumn{2}{|c|}{$\begin{array}{l}\text { Kadang- } \\
\text { kadang } \\
\text { (3) }\end{array}$} & \multicolumn{2}{|c|}{$\begin{array}{c}\text { Sering } \\
\text { (4) }\end{array}$} & \multicolumn{2}{|c|}{$\begin{array}{c}\text { Selalu } \\
(5)\end{array}$} \\
\hline & $\mathrm{n}$ & $\%$ & $\mathrm{n}$ & $\%$ & $\mathrm{n}$ & $\%$ & $\mathrm{n}$ & $\%$ & $\mathrm{n}$ & $\%$ \\
\hline $\begin{array}{l}\text { Membatasi hubung- } \\
\text { an dengan orang } \\
\text { lain }\end{array}$ & 50 & 57,5 & 14 & 16,1 & 17 & 19,5 & 3 & 3,4 & 3 & 3,4 \\
\hline $\begin{array}{l}\text { Senang dengan pe- } \\
\text { nampilan gigi/ gusi/ } \\
\text { gigi palsu }\end{array}$ & 32 & 36,8 & 27 & 31,0 & 10 & 11,5 & 9 & 10,3 & 9 & 10,3 \\
\hline $\begin{array}{l}\text { Khawatir dengan gi- } \\
\text { gi/gusi/gigi palsu }\end{array}$ & 30 & 34,5 & 23 & 26,4 & 24 & 27,6 & 7 & 8,0 & 3 & 3,4 \\
\hline $\begin{array}{l}\text { Tidak percaya diri } \\
\text { dengan } \\
\text { gigi/gusi/gigi palsu }\end{array}$ & 34 & 39,1 & 15 & 17,2 & 26 & 29,9 & 9 & 10,3 & 3 & 3,4 \\
\hline $\begin{array}{l}\text { Tidak nyaman de- } \\
\text { ngan orang lain ka- } \\
\text { rena gigi/gusi/ gigi } \\
\text { palsu }\end{array}$ & 32 & 36,8 & 12 & 13,8 & 21 & 24,1 & 13 & 14,9 & 9 & 10,3 \\
\hline
\end{tabular}

Pengukuran kualitas hidup pada lansia di UPT Pelayanan Sosial Lanjut Usia Binjai terbanyak dalam kategori cukup $(47,1 \%)$, yaitu pada usia 60 64 tahun ada 11,5\% dan pada usia > 65 tahun ada $35,6 \%$ (Tabel 8).

Tabel 8. Kategori kualitas hidup berdasarkan usia lansia di UPT Pelayanan Sosial Lanjut Usia Binjai

\begin{tabular}{cccccccccc}
\hline & \multicolumn{8}{c}{ Kualitas hidup } & \\
\cline { 2 - 7 } $\begin{array}{c}\text { Usia } \\
\text { (Tahun) }\end{array}$ & $\begin{array}{c}\text { Sangat } \\
\text { baik }\end{array}$ & Baik & Cukup & Buruk & \\
\cline { 2 - 7 } & $\mathrm{n}$ & $\%$ & $\mathrm{n}$ & $\%$ & $\mathrm{n}$ & $\%$ & $\mathrm{n}$ & $\%$ & \\
\hline $60-64$ & 5 & 5,7 & 3 & 3,4 & 10 & 11,5 & 1 & 1,1 & 19 \\
$>65$ & 9 & 10,3 & 24 & 27,6 & 31 & 35,6 & 4 & 4,6 & 68 \\
Total & 14 & 16,1 & 27 & 31,0 & 41 & 47,1 & 5 & 5,7 & 87 \\
\hline
\end{tabular}

Analisis uji Chi square pada Tabel 9 yang menunjukkan hubungan antara jumlah gigi sehat dengn kualitas hidup yaitu pada lansia yang mempunyai gigi $>21$ gigi mempunyai kualitas hidup yang sangat baik sebanyak $100 \%$, sedangkan pada lansia yang tidak mempunyai gigi kualitas hidupnya dalam kategori cukup sebanyak 55\%.
Tabel 9. Kategori kualitas hidup lansia berdasarkan jumlah gigi yang sehat di UPT Pelayanan Sosial Lanjut Usia Binjai

\begin{tabular}{|c|c|c|c|c|c|c|c|c|c|}
\hline Jumlah gig & & & & $\mathrm{Ku}$ & litas hidu & & & & \\
\hline $\begin{array}{l}\text { sehat yang } \\
\text { ada }\end{array}$ & & $\begin{array}{l}\text { ngat } \\
\text { aik }\end{array}$ & & aik & Cukup & & & $\begin{array}{c}\text { Jum- } \\
\text { lah }\end{array}$ & $\begin{array}{l}\text { Analisis } \\
\text { Statistik }\end{array}$ \\
\hline & $\mathrm{n}$ & $\%$ & $\mathrm{n}$ & $\%$ & $\mathrm{n} \%$ & $\mathrm{n}$ & $\%$ & & \\
\hline $\begin{array}{l}\text { Tidak ada } \\
\text { gigi }\end{array}$ & - & - & 6 & 30,0 & 1155,0 & 3 & 15,0 & 20 & \\
\hline $1-10$ gigi & 2 & 4,7 & 14 & 32,6 & 2558,1 & 2 & 4,7 & 43 & \\
\hline 11-20 gigi & 5 & 29,4 & 7 & 41,2 & 529,1 & - & - & 17 & \\
\hline$>21$ gigi & 7 & 100 & - & - & - & - & - & 7 & \\
\hline Total & 14 & 16,1 & 27 & 31,0 & 4147,1 & 5 & 5,7 & 87 & \\
\hline
\end{tabular}

\section{PEMBAHASAN}

Responden yang tidak menggunakan gigi tiruan yaitu sebanyak $97,7 \%$, sedangkan yang menggunakan hanya 2,3\% dengan kondisi baik. Hasil penelitian ini jauh lebih rendah dibandingkan penelitian Murariu dkk. yaitu $51,1 \%$ pada responden yang berada di Panti Jompo Romania. Hal ini kemungkinan disebabkan karena UPT Pelayanan Sosial Lanjut Binjai adalah panti jompo milik PEMPROVSU yang seluruh biayanya ditanggung oleh pemerintah.

Kondisi rongga mulut yang sering ditemukan pada lansia yaitu mulut kering, gigi mengalami atrisi, karies, gigi mobiliti, dan lain-lain. ${ }^{4}$ Pada penelitian ini persentase yang paling tinggi adalah gigi mobiliti $(32,2 \%)$. Hal ini disebabkan oleh adanya perubahan proses fisiologis pada proses penuaan jaringan yang mengakibatkan terjadinya resorbsi jaringan tulang alveolar. Persentase mulut kering yaitu 31,0\%, menurut Hasibuan keluhan mulut kering sering ditemukan pada lansia disebabkan oleh adanya perubahan atropi pada kelenjar saliva sesuai dengan pertambahan usia yang akan menurunkan produksi saliva. $^{5}$

Rerata DMFT pada lansia di UPT Pelayanan Sosial Lanjut Usia Binjai yaitu 19,1. Rerata yang tertinggi yaitu missing sebanyak 18,1. Hal ini berhubungan dengan jumlah gigi yang ada di rongga mulut yaitu pada lansia 60-64 tahun yang tidak mempunyai gigi hanya 2,3\%, sedangkan pada usia > 65 tahun sebanyak 20,7\%. Angka ini hampir sama dengan hasil survei yang dilakukan oleh WHO di beberapa negara misalnya di Indonesia ada $24 \%$ lansia yang tidak memiliki gigi di atas usia 65 tahun, Polandia 25\%, Romania 26\%, dan USA 26\%. ${ }^{10}$

Pada dimensi fungsi fisik terlihat bahwa responden selalu membatasi makanan sebanyak 77,0\%, selalu kesulitan menggigit dan mengunyah $75,9 \%$, dan selalu mengalami masalah dalam berbicara yaitu $57,5 \%$. Hal ini kemungkinan disebabkan ka- 
rena terjadinya perubahan pada rongga mulut lansia. Salah satunya adalah kehilangan gigi yang dapat mempengaruhi proses pengunyahan dan fungsi suara. Penelitian Murariu pada lansia yang berada di Panti Jompo Romania pada tahun 2010 terlihat bahwa lansia yang selalu membatasi makanan $55 \%$ dan selalu kesulitan dalam menggigit dan mengunyah yaitu 53,3\%. Hal ini kemungkinan karena pada penelitian Murariu banyak responden yang menggunakan gigi tiruan yaitu $51,1 \%$, sedangkan pada penelitian ini hanya 2,3\% yang menggunakan gigi tiruan. $^{11}$

Pada dimensi rasa sakit/ketidaknyamanan, lebih dari $50 \%$ responden yang tidak pernah menggunakan obat-obatan untuk menghilangkan rasa sakit $(88,5 \%)$, dan tidak pernah merasa sensitif terhadap makanan panas, dingin dan manis $(71,3 \%)$. Seperti penelitian Murariu pada lansia yang berada di Panti Jompo Romania pada tahun 2010, yaitu lebih dari $50 \%$ responden yang tidak pernah menggunakan obat-obatan untuk menghilangkan rasa sakit $(57,8 \%)$, dan yang tidak pernah mengalami sensitif terhadap makanan panas, dingin dan manis $(57,8 \%)$. Banyak lansia yang tidak pernah minum obatobatan untuk menghilangkan rasa sakit di daerah rongga mulut dengan alasan menghindari kemungkinan terjadinya kontra indikasi obat-obatan yang biasanya dikonsumsi untuk pengobatan penyakit sistemik. ${ }^{11}$

Dari segi dimensi psikososial, 57,5\% tidak pernah membatasi hubungan, 34,5\% tidak pernah khawatir dengan penampilan gigi/gusi/gigi palsu, selalu percaya diri dengan gigi/gusi/gigi palsu $(39,1 \%)$, dan selalu merasa nyaman dengan orang lain karena gigi/gusi/gigi palsu sebanyak 36,8\%. Hal ini kemungkinan disebabkan karena gangguan fungsi gigi lebih menonjol dibandingkan kehidupan sosialnya, sementara di negara-negara maju seperti Australia lebih berdampak pada kehidupan sosial. ${ }^{12}$

Kategori kualitas hidup berdasarkan usia, terlihat lansia di UPT Pelayanan Sosial Lanjut Usia Binjai pada usia 60-64 tahun mempunyai kualitas hidup dengan kategori sangat baik sebanyak 5,7\%, dan pada usia >65 tahun yang mempunyai kualitas hidup dengan kategori sangat baik sebanyak 10,3\%. Hasil penelitian ini menunjukkan adanya hubungan jumlah gigi yang sehat dengan kualitas hidup. Pada responden yang mempunyai jumlah gigi sehat masih > 21 gigi sebanyak 100\% mempunyai kualitas hidup sangat baik, sedangkan pada responden yang tidak mempunyai gigi tidak dijumpai seorangpun dalam kategori kualitas hidup sangat baik. Pada responden yang mempunyai 1-10 gigi sehat memiliki kualitas hidup dengan kategori cukup sebanyak $58,1 \%, 32,6 \%$ responden yang memiliki kualitas hidup dalam kategori baik, dan hanya 4,7\% responden yang memiliki kualitas hidup pada kategori sangat baik. Sebaliknya responden yang mempunyai gigi sehat 11-20 gigi memiliki kualitas hidup dalam kategori baik sebanyak 41,2\% dan sangat baik sebanyak $29,4 \%$. Selain itu, pada responden yang mempunyai gigi sehat $>21$ gigi memiliki kualitas hidup dalam kategori sangat baik mencapai $100 \%$. Makin banyak jumlah gigi, maka semakin tinggi persentase responden yang memiliki kualitas hidup dalam kategori baik dan sangat baik. Hal ini menunjukkan bahwa jumlah gigi dapat mempengaruhi kualitas hidup seseorang, misalnya dalam proses pengunyahan, dan fungsi suara akan sangat terganggu bila keadaan giginya memprihatinkan. Sama halnya dengan penelitian Gerritsen pada 435 orang lansia dengan menggunakan indeks GOHA, hasilnya menunjukkan bahwa responden yang mempunyai >20 gigi maka kualitas hidupnya lebih baik daripada lansia dengan $<20$ gigi. Gerritsen juga menyatakan pada lansia yang memiliki hanya $<9$ gigi berpeluang lebih besar terkena dampak sosial terhadap kesehatannya dari pada terkena penyakit hipertensi atau alergi. Penelitian ini membuktikan bahwa jumlah gigi yang tinggal di rongga mulut pada lansia dapat mempengaruhi kualitas hidupnya. $^{13}$

\section{Daftar Pustaka}

1. Lestari S. Hubungan perilaku dengan status kebersihan mulut dan karies gigi pada lansia. JITEKGI 2011; 8 (1): 32-5.

2. Cahyati WH. Beberapa faktor yang berhubungan dengan karies gigi pada lanjut usia (studi kasus di Panti Wreda Kota Semarang). Kemas Universitas Negeri Semarang 2005; 1 (1): 22-30.

3. Lestari S, Boesro S, Sudhana W. Gambaran perilaku dan status kesehatan gigi dan mulut lansia di Puskesmas Kecamatan Kemayoran Jakarta Pusat. M.I. Kedokteran Gigi Universitas Trisakti 2005; 20 (62): 83-9.

4. Natamiharja L. Status dan kebutuhan pelayanan kesehatan gigi lansia di Kota Madya Medan. J Kedokteran Gigi UI 2000; 7 (1): 14-22.

5. Hasibuan. Keluhan xerostomia (mulut kering) ditinjau dari penyebab dan penanggulangannya. http:// graha-cendikia.wordpress.com/index.html. (3 Agustus 2012).

6. Dharmautama M, Koyana AT, Kusumawati A. Tingkat keparahan halitosis pada manula pemakai gigitiruan. Dentofasial FKG Universitas Hasanuddin 2008; 7 (2): 107-14.

7. Mudjari I, Susilowati. Dampak maloklusi terhadap kualitas hidup. JITEKGI 2011; 8 (1): 41-5.

8. Atchison KA. The geriatric oral health assessment index. In: Slade GD. Measure oral health and quailty of life. Department of Dental Ecology School of 
Dentistry: North Carolina, 1997: 71-6.

9. Situmorang N. Penyakit gigi dan mulut serta pengaruhnya terhadap kualitas hidup. dentika Dent J 2001; 6 (1): 184-88.

10. Petersen PE, Yamamoto $\mathrm{T}$. Improving the oral health of older people: the approach of the WHO global oral health programme. Community Dent Oral Epidemiol 2005; 33: 81-92.

11. Murariu A, Hanganu C, Bobu L. Evaluation of the reliability of the geriatric oral health assessment index (GOHAI) in institutionalised elderly in Romania: a pilot study. OHDMBSC 2010; 9 (1): $1-5$.

12. Pintauli S, Natamiharja L. Dampak sosial keadaan gigi dan mulut pada pengunjung klinik gigi fakultas dan Puskesmas di Kota Medan: suatu studi pendahuluan. dentika Dent J 2005; 10 (1): 16-21.

13. Gerritsen AE, Allen PF, Witter DJ, Bronkhorst EM, Creugers N. Tooth loss and oral health-related quality of life. Biomed Central 2010; 6 (126): 1-11. 